\title{
Concepts in Linguistics - Concepts in Natural Language
}

\author{
Gisela Harras \\ Institut für deutsche Sprache \\ Mannheim
}

\begin{abstract}
This paper deals with different views of lexical semantics. The focus is on the relationship between lexical expressions and conceptual components. First the assumptions about lexicalization and decompositionality of concepts shared by the most semanticists are presented, followed by a discussion of the differences between two-level-semants and one-level-semantics. The final part is concentrated on the interpretation of conceptual components in situations of communication.
\end{abstract}

\section{The Classical View}

Following the classical scholastic view linguistic signs are related to two types of entitites:

(a) the type of cognitive entitites, concepts

(b) the type of entities of the external world

There is a direct relation between signs and concepts, between concepts and entities of the external world, and there is an indirect relation between signs and entities of the external world being mediated by concepts. These relations have been represented by the well known semiotic triangel (first in Ogden and Richards, 1953; cf. Lyons, 1977, 96.):

cognitive entity: concept

B

A

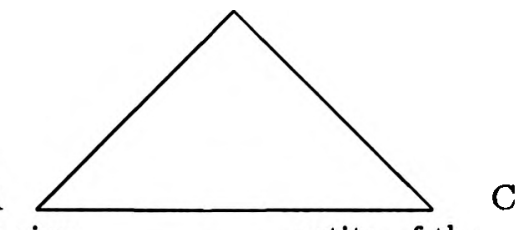

linguistic item: sign

entity of the external world: referent

This representation is in accordance with the traditional analysis of signification as expressed in the famous scholastic maxim: 
"Voces significant res mediantibus conceptibus"

(Words signify things by means of mediating concepts)

As Lyons has pointed out there is considerable disagreement about the details of the triadic analysis of signification (cf. Lyons, 1977, 99):

- should A be defined as a physical or a mental entity?

- what is the psychological or ontological status of $B$ ?

- is C something that is referred to by uttering the sign?

(If this would be so, how can signs while they are not used signify something?)

- is $\mathrm{C}$ the totality of things that might be referred to by uttering the sign?

- is $\mathrm{C}$ some typical or ideal representative of this class?

In modern semantics there are two ways of answering those questions:

(1) the post Saussurean view: A and B are both psychological (or mental) entitites. They constitute the linguistic sign als having two aspects: the aspect of the signifiant, image accoustique, i.e. the phonological form, and the aspect of the signifié, the concept. The meaning of a linguistic sign is then, following Saussure, composed of the intrinsic relation between signifiant and signifié and the meaning relations the sign holds to all the other signs of a given la nguage, the valeur.This Saussurean conception has been modified by modern semanticists in the following way: Concepts (which are not clearly defined by Saussure) are considered as abstract and collective entities in contrast to individual mental images, ideas or thoughts. They are relatively stable (in contrast to most psychological views) and highly structured. The principles of structuring concepts are part of the human cognitive endowment, they are innate. Linguistic expressions encode concepts as their semantic content cut out of the conceptual pool which is universal, i.e. independent of any existing language. Because of this twofold relationship of linguistic expressions and concepts as semantic content and universal conceptual structure this kind of semantics has also been called two-level-semantics. It has been worked out by Bierwisch, Lang, Wunderlich, Schwarz.

(2) A second issue in modern semantics is the view that linguistic forms are immediately related to concepts without any intermediate level of semantic content. It has been worked out by Jackendoff, Lakoff, Fauconnier, Langacker.

In spite of the difference between the two kinds of semantics there are some common assumptions concerning the relation between linguistic expressions and concepts:

First of all, it is a common assumption that there are linguistic expressions which don't encode any concept at all, as for instance pronouns, interjections, the single words of an idiom or a formula like good bye or hello.

A further common assumption is that some concepts have no corresponding word, and can be encoded only by a phrase. Speakers of French don't have a 
word for the concept expressed by engl. sibling or german Geschwister, but may nonetheless have the concept of "sibling" characterized as child of same parents, and object of many beliefs and expectations, a concept which has frère and soeur as subcategories. We don't have a word for "wheeled vehicle" or "bad person". The question if $l$ exical gaps are generally or in a certain language accidental or systematically distributed is an open question. There seems to be some evidence that lexical gaps are generally high-leveled in the hierarchy of concepts and constitute generic terms for a range of lower leveled concepts and words.(cf. Fellbaum 1996.)

The third common assumption concerns the overall phenomenon that words can - in an actual use - encode a whole range of concepts. Suppose Mary says to Peter:

(1) Open the bottle

In most situations, she would be understood as asking him to uncork or uncap the bottle depending on the properties of the referent of the direct object: thus opening a corked bottle means uncorking it, and so on. Uncorking a bottle may be the standard way of opening it, but another way is to saw off the bottom, and on some occasion, this might be what Mary was aking Peter to do. Or, suppose Mary says to Peter:

(2) Open the washing machine

In most situations, she will probably be asking him to open the lid of the machine. However, if Peter is a plumber, she might be asking him to unscrew the back; in other situations, she might be asking him to blow the maschine open, or whatever.

The general point is that expressions like open can be used to convey indefinitely many concepts. It is impossible for all of these to be listed in a lexicon. Nor can they be generated by taking only the linguistic context, particulary the direct object, into account. It seems reasonable to conclude that a word like open is often used to convey a concept that is encoded neither by the word itself nor by the verb phrase open $X$. (Cf. for similar examples: Searle 1980; Pinkal 1995; Pustejovsk y 1995; Sperber/Wilson 1998.) The common claim is that lexical meaning is flexible, but not structureless, and from this follows that lexical meanings can be assigned a description of its structure in terms of features or meaning postulates.

The claim of decompositionality of the conceptual content of words is far from being without problems: Johnson-Laird (1987) tested the human faculty of giving definitions of word meanings by non experts. He choose four levels of semantic complexity, and predicted that semantically complex verbs, such as watch and lend, would be easier to define than the semantically simplest verb, such as see and own. This prediction was confirmed: It was easy for the subjects to break down the meani ng of a complex verb into simpler components for which there are corresponding words, but it was hard for the subjects to find such components for a simple verb. 
Some semanticists therefore assume that there is a set of semantic primitives that cannot be further analyzed, such as "cause", "bring about", "vision", "human", "thing", "place" and so on. They are the basic features for building up more complex word meanings. (Cf. already Katz/Fodor 1963; Wierzbicka 1972; Bierwisch 1992; Lang 1994.) But even if we admit that there is only a subset of word meanings which can be analyzed in terms of features there are some problems left: The problems concern the organizatio $\mathrm{n}$ of the features as well as their logical status. The features "animal" and "concrete object" are analytical implications of the meanings of cat and car respectively, they have the status of meaning postulates unter the condition that the words are used in a standard non-marked context. Meaning postulates may vary from language to language (cf. Schwarze, 1987.) The German preposition auf analytically implies "in contact with $(\mathrm{x}, \mathrm{y})$ " whereas the french preposition sur does not analytically imply "in contact with $(x, y)$ ", cf.:

(3) L'avion plane sur la ville

$*$ Das Flugzeug schwebt auf der Stadt

Another group of word meanings can well be described by components, but they have another organization and logical status than meaning postulates. This is the case with words like elephant, tiger, lemon, water and so on, so called natural kind terms. Most speakers of English are able to say what an elephant is, they have seen an elephant in the zoo, or a picture of one, and they know something about the nature of the animal. Yet the term is a theoretical one (cf. JohnsonLaird 1987, 203.) It designate $s$ a set of creatures within our categorization of animals. Our knowledge of such matters is far from complete. We don't know for certain what the essentials of elephanthood, tigerhood or cathood actually are. These words notoriously give rise to the problem of delimiting what should be said in a dictionary and what should be said in an encyclopedia, because it is doubtful whether there are any necessary and sufficient conditions for defining them. (cf. Putnam 1975; Lutzeier 1985; Schwarze 1987; Harras 1991.) If someone tells me that he saw an elephant in the zoo, then I will interpret her utterance to mean that she saw a large four-legged mammal with tusks and a trunk. But these characteristics are not essential, and they are not mere inductions, since to check them inductively presupposes some independent method for first identifying elephants; in fact they are part of our "theory" of elephants (cf. Johnson-Laird 1987; Putnam 1975.) which tells us that the stereo- or prototypical member of the class has each of these attributes. The lexical meaning of elephant must therefore be represented by a schema of the stereo- or prototypical animal, a mental model with a set of default values, that is, specific values for variables that can be assumed in the absence of information to the contrary. Default values have a special status concerning their contribution to the truth conditions of the sentence where the word occurs. Necessary components of a word's meaning support valid inferences, default values hold onl y in the case that nothing is asserted to the contrary. Stereotypes as the content of the meaning of natural kind words may vary from culture to culture, they are 
not necessarily dependent on a certain language. (cf. Putnam 1975; Schwarze 1987.) The same is true of words for artefacts like knife, hammer, plate, table and so on.

After we have known the common assumptions of most of modern semantic theories let's now have a look at their differences. I will first discuss the so called two-level-semantics.

\section{Two Conceputal Domains: The Two-Level-Semantics}

Concepts appear within this theory in two domains:

- in the domain of semantic form as the conceptual content of a lexical expression

- in the domain of conceptual structure in terms of which the actual interpretation of a given linguistic expression is specified.

The domain of semantic form is related to the language-dependent representation of a conceptual structure, the conceptual structure is related to the universal representation of encyclopedic background knowledge, contextual information and situational conditions. The semantic form of a lexical expression constitutes its core meaning, that is, the context-free meaning as stored in long term memory. The domain of conceptual structure is needed for the interpretation of a given lexical expression in a certain context and situation. The focus of two-level-semantics is upon the representational aspect of meaning as well as on the dynamic procedural aspect of information processing. This kind of semantics is therefore claimed to be a part of cognitive science and the cognitive information processing system does not necessarily have to be a human being.

The distinction between semantic form and conceptual structure is mainly motivated by the overall phenomenon of the underdetermination of linguistic expressions. Well known examples are the following (cf. Bierwisch/Schreuder 1992; Schwarz 1992):

(1) John left the institute an hour ago

(2) John left the institute a year ago

Linguistically, we know that John is a proper name by means of which we may refer to male persons identified by this name. This is the information represented in the semantic form of John. Conceptually, we have a specific knowledge about each person named John we happen to know. This knowledge has nothing to do with the knowledge of English.

In (1) the institute most likely refers to a building and leave is interpreted as a change of place, while in (2) the institute refers to an institution and leave is interpreted as a change of profession. The different time intervals in (1) and (2) bring in different background knowledge not contained in any of the expressions in (1) and (2).

Another case of linguistic underdetermination is the following:

(3) The office is closed 
If (3) is uttered by a servant of the office the office door may be open, while uttered in another situation the door may be locked. In all these cases the interpretation of a given utterance is first based on the semantic form of the expressions which activates the relevant background knowledge of conceptual structures. The semantic form is only a part of the final interpretation, or more precisely: the conceptual interpretation of a given semantic form would have to contain this semantic form as a proper substructure, or at least the weaker condition must hold: the semantic form has to be embeddable into the conceptual interpretation, with embedding to be conceived as the relation of a partial model to a more complete model the partial model is compatible with. (cf. Bierwisch/Schreuder 1992; Kamp/Reyle 1994.)

The strucure of a full lexical entry contains four kinds of lexical information (cf. Bierwisch/Lang 1987; Bierwisch/Schreuder 1993; Lang 1994):

- the phonetic form represented by phonological features

- the grammatical features, syntactic category, finiteness

- the semantic form represented by categorized variables $x, y, P$, formal components such as $C, \subseteq, \rightarrow, \leftrightarrow$ and material components such as CAUSE, BECOME, PLACE.

- the argument structure of verbs and some nouns.

The natural domain of two-level-semantics are simple and complex verbs, dimension adjectives and prepositions (cf. Wunderlich, 1997). Their semantic form is much more structured than the semantic form of nouns, especially words for natural kinds or artefacts like cat, camel, lemon or chair, knife and car. The conceptual analysis of these words may be infinite and the object of all kinds of contingent knowledge. The semantic form of words for natural kinds is poor; it contains only the info rmation NATURAL KIND, ANIMAL; their conceptual structure may be extremely rich. The semantic form of artefacts contains the information of specific functions that allows for inferences about the relation between their referents and human activities. In accordance to this assumption the representations of the semantic form of cat and camel on the one side and chair and knife on the other are the same in all relevant aspects. The differences between cats and camels and between chairs a nd knifes are captured in the conceptual structure. This strategy implies a problematic division of labour, that is: linguistics is responsible for the formal reduction, while psychology, philosophy or whatever world science is responsible for the material instanciation. However, besides this very general problem, there are at least two serious problems left, one of which concerns rather methodological difficulties, whereas the other relates to more fundamental questions about information processing:

- the first problem concerns the distinction between assigning semantic and conceptual information to a given lexical expression. As Lang $(1994,28)$ has pointed out, the fact that the conceptual structure is inaccessible to direct observation may leed to a thoughtless overgeneralization of semantic properties of a given language. This may be true even if semanticists respect 
the caveat principle of cross-linguistic and intermodal comparing. (cf. Lang 1994; Meyer 1992; Kriffka/Wenger 1990; Dölling 19 92.)

- the second problem concerns the question of how human beings are capable to convey and understand the relevant information of a given linguistic expression, if most of their utterances are semantically underdetermined. I will turn to this problem in the last part of my paper.

\section{One Domain of Concepts: One-Level-Semantics (Jackendoff)}

The fundamental assumption of Jackendoff $(1983 ; 1990 ; 1997$.$) is that the gram-$ matical structure of natural languages offers an important new source of evidence for (the theory of) cognition. The grammatical structure of a natural language is regarded as a triple, consisting of phonological structures, syntactic structures and conceptual structures. Phonological, syntactic and conceptual structures are determined by phonological, syntactic and conceptual formation rules. The three structures are connected by corresponding rules (cf. Jackendoff 1997, 39.):

$\begin{array}{lll}\begin{array}{l}\text { phonological } \\ \text { formation } \\ \text { rules }\end{array} & \begin{array}{l}\text { syntactic } \\ \text { formation } \\ \text { rules }\end{array} & \begin{array}{l}\text { conceptual } \\ \text { formation } \\ \text { rules }\end{array} \\ \mid \begin{array}{l}\text { phonological } \\ \text { structures (PS) }\end{array} & \begin{array}{l}\text { syntactic } \\ \text { structures (SS) }\end{array} & \begin{array}{l}\text { conceptual } \\ \text { structures (CS) }\end{array}\end{array}$

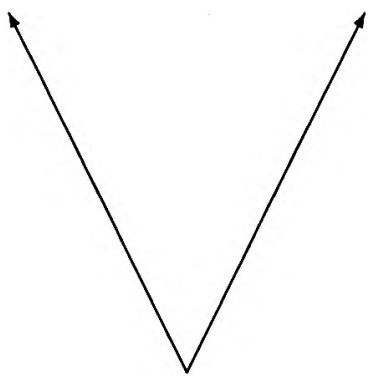

PS-SS

corresponding rules

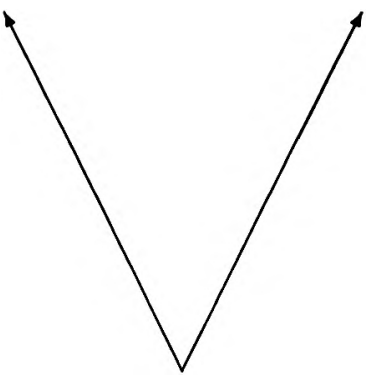

SS-CS

corresponding rules

Phonological and syntactic structures are modules of their own, whereas conceptual structures must be linked to all the other sensory modalities. In contrast to two-level-semantics Jackendoff (and others like Fauconnier 1985; Lakoff 1987; 
Langacker 1988; Pustejovsky 1995.) does not postulate a level of semantic form as an interface between grammar and concepts: "...there is not a form of mental representation devoted to a strictly semantic level of word meanings, distinct from the level at which linguistic and nonlinguistic information are compatible. This means that if, as is often claimed, a distinction exists between dictionary and encyclopedia lexical information, it is not a distinction of level; these kinds of information are cut from the same cloth." (Jackendoff 1983, 110.)

This position has at least two consequences:

- if semantics takes into account that lexical meanings are highly context dependent then a one-level conception has to match all (possible) contexts or phrase structures to a given lexical item.

- There must be some rules on the level of the conceptual structure allowing for re-interpretations of a lexical expression in a certain context and situation.

The first claim is fulfilled in so far as the rules of corresponding syntactic and conceptual structures are applied to syntactic structures of different complexity: as $V^{0}$ (the simple verb), as $V^{1}$ (verb + direct object), $V^{2}$ (verb + direct object + indirect object), $V^{3}$ (verb + direct object + indirect object + prepositional object) and so on. So we get different (complex) lexical entries for give, give something, give something to someone or give something to someone on some occasion. (cf. Jackendoff 1990) The aim of Jackendoff (and other one-levelsemanticists) obviously is not to build up a genuine lexicon of a given language, but rather to show the above mentioned quality of natural language as a source of evidence of human cognition.

The second claim is fulfilled by introducing preference rules for stereo- or prototype concepts such as BIRD, FRUIT or VEGETABLE. Preference rules are like to default values: They mark the best example in a subcategory of a higher category, so as for instance ROBIN as the best example of the category BIRD.

Preference rules are not only applied to nouns constituting words for natural kinds or artefacts, they are also applied to verbal concepts (cf. Jackendoff 1983, 150):

(1) I must have looked at that a dozen times, but I never saw it

(2) I must have seen that a dozen times, but I never noticed it

(1) and (2) raise a serious problem if we assume that see has a unified single meaning: The meaning of see in (1) is used to deny its meaning in (2). " $\mathrm{x}$ sees $y$ " means something like ' $x$ 's gaze goes to $y$ '. In this sense of see $_{1}$ the direct object may alternate with prepositonal phrases:

(3) John saw into the kitchen

(4) John saw under the chair

(4) may mean that John's gaze terminated at a certain point under the chair or that his gaze passed under the chair to a point beyond. So $s e e_{1}$ is very similar to a verb of motion:

(5) John saw the flying saucer from his living room 
In (1) is asserted that I never became aware of the object; so we get see $_{2}$ with the meaning 'y comes to x's visual awareness'. It is precisely this awareness that is not necessary for the assertion of see in (2). A sentence like

(6) John sees Mary

is not in the same way ambiguous as We went to the bank: The speaker does not have one reading or the other in mind. (6) appears to intend both that John's gaze went to Mary and that Mary enters John's awareness, but the presence of both ' $x$ 's gaze goes to $y$ ' and 'y comes to x's awareness' is not a necessary condition for the use of the verb see, they are stereotypical devices, captured by preference rules.

The one-level-semantics of Jackendoff and others obviously does not give rise to the problem of the distinction between what is a language-dependent concept and what is a language-independent concept, a problem two-level-semantics is very much concerned with. However, the other problem of how people are capable of conveying and understanding the relevant meaning in semantically underdetermined utterances is left. I will turn to this problem next.

\section{Meaning, Understanding and Human Communication}

Communication seems to be an extremely ambiguous expression in English. In all cases of its occurrence it has obviously something to do with human interpretation: we may interpret all kinds of images, signs, natural states and behaviour of persons as something conveying meaning. This can be illustrated by the following example (cf. Carston 1999): Imagine observing a scene in which a man lowers himself, head and arms first, down into a hole in the ground while another man holes onto his legs, swiveling his eyes leftwards in our direction and jerking his head quite violenty from left to right. Very few observers will represent this scene to themselves as I have described it and leave it at that; most of us will try to find some plausible beliefs, desires and/or intentions that we can attribute to these two men, some set of mental states which will explain their behaviour. We'll take the head movement of the second man to be, not some involuntary tic he developed upon seeing us, but rather a movement desig ned to make it evident to us that he wants our intention and has something to tell us. We might even infer what the intended message is, something like "I want you to help me" perhaps.

The second man's behaviour, his swiveling his eyes and jerking his head, counts for us as an act of communication under the following conditions:

- the man's behaviour is intentional, it is an action;

- the intention is directed towards us

- the intention contains a message, so that: the man intended us to recognize his intention to communicate to us that he wants some help.

These conditions of human communication have been worked out in detail by Grice (Grice 1989). Following him, an act of communication can be defined als follows: A speaker $\mathrm{S}$ communicates something to a hearer $\mathrm{H}$, iff 
(i) $\mathrm{S}$ intends $\mathrm{H}$ to react in a certain way $\mathrm{r}$

(ii) $\mathrm{S}$ intends $\mathrm{H}$ to recognize (i)

(iii) $\mathrm{S}$ intends $\mathrm{H}$ to react in the way $\mathrm{r}$ by means of recognition of (i)

Communication is thus regarded as a means of influencing people by using signs in order to bring about a certain reaction of people presupposing that the recognition of the intention of bringing about the reaction will be a sufficient reason for people to react in the intended way. An important point is that influencing people counts only as a case of communication, if it is intended to be recognized. In a given situation an imperative "go downstairs" may not be very different from a kick. Both kinds of inf luencing may bring about the same reaction of an adressee, that is: to go downstairs, but only the imperative is a case of communication in the Gricean sense (cf. Keller 1995).

The Gricean conception of communication is not necessarily restricted to linguistic communication. What are then the special conditions of linguistic communication? First of all we would say that the content of the act of communication, the utterance, has to be understood in the intended way. Understanding the speaker's utterance is necessary for the hearer to react in the intended way. If someone says to me:

\section{(1) Could you pass me the salt}

I first have to understand that the speaker uttered a request in order to react in the intended way, that is: to pass him the salt.

The definition of Gricean communication seems to suggest that the hearer has the role of a pure recipient of speaker's intention. But, following Grice, communication demands not only intentions on the side of the speaker but also cooperation on both sides. Communication is a cooperative enterprise governed by a general cooperative principle and some more specific maxims. The cooperative principle is about the presupposed appropriateness of a given conversation, i.e. a case of linguistic communication: "Make your conversational contribution such as is required, at the stage at which it occurs, by the accepted purpose of direction of the talk exchange in which you are engaged." (Grice 1989, 26.) The specific maxims concern the quantity of information (be informative), the quality of information (be sincere), the relevance of information (be relevant) and the modality of information (be clear).

The general cooperative principle and the maxims of communication seem to be trivial on the first account. But Grice himself and legions of linguists consider this principle and the maxims to be a powerful instrument for explaining how people convey and understand relevant information. Let's take a very innocent example: Someone saying

(2) The kettle is black

thereby means that the outside of the iron kettle is covered with dark brown grease stains (example from Travis 1997). The addressee who can see the kettle would certainly not say that (2) is false, even if he has evidence that, taken (2) literally, it is actually false! In interpreting what the speaker intends him to 
understand, namely that the kettle is now darker than it has been some time before, the hearer must rely on the following assumptions:

- S and I are in the same situation of communication

- $\mathrm{S}$ has communicated to me that $\mathrm{p}$ (the kettle is black)

$-p$ is not true in the situation we are in

- $S$ is respecting the general principle of cooperation

- $S$ is respecting the maxim of quality, i.e. he does not want to tell me something false

- given the situation we are in and the fact that $S$ is cooperative, $S$ intends me to unterstand that $q$ (the kettle is now darker than it has been some time before).

This is the rough mechanism of what Grice has called a conversational implicature in contrast to implications which are due to the semantics of the expressions in a given utterance. It is quite clear that implicatures rely on different kinds of information:

- the information provided by the content of the speaker's utterance, i.e. what is linguistically said;

- the information provided by the special situation speaker and hearer are in;

- the information provided by the situation type of communicating.

These kinds of information have to be completed by a fourth one for cases in which the state asserted by the speaker's utterance is not - as in our example - a part of the situation speaker and hearer are in. This kind of information is provided by all kinds of background knowledge about how things are or have to be. Finally - the most crucial condition - the knowledge constituting all these types of information - or at least a part of it - has to be available for both speaker and hearer, i.e. it has to be common knowledge. Most of the traditional definitions have to struggle with an infinite regress by explaining common knowledge in terms of individual knowledge, like:

\section{A knows $\mathrm{X}$ \\ $B$ knows $X$ \\ A knows that $B$ knows $\mathrm{X}$ \\ $B$ knows that $A$ knows $X$}

A knows that $B$ knows that $A$ knows $X$

$B$ knows that $A$ knows that $B$ knows $X$

$A$ knows that $B$ knows that $A$ knows that $B$ knows $X$

$B$ knows that $A$ knows that $B$ knows that $A$ knows $X$

and so on: ad infinitum

It is quite obvious that, when people make use of common knowledge, they do not pursue an infinite regress of this kind. The analysis in terms of invidual knowledge is not at all appropriate to give a notion of real common knowledge. 
Devlin (1997) has proposed an explanation in terms of situation theory: The act of two persons $\mathrm{A}$ and $\mathrm{B}$ having common knowledge of a fact, event or circumstance $\mathrm{X}$ constitutes a situation $\mathrm{s}$. The situation $\mathrm{s}$ is a common knowledge situation for $\mathrm{A}$ and $\mathrm{B}$ to have common knowledge of $\mathrm{X}$, iff:

(i) $\mathrm{s}$ is a situation supporting the individual knowledge of $\mathrm{A}$ and $\mathrm{B}$ :

$\mathrm{s} \mid \ll A$ knows $X \gg \wedge \ll B$ knows $X \gg$

(ii) both $\mathrm{A}$ and $\mathrm{B}$ know that $\mathrm{s}$, the situation they are in, is one of common knowledge:

$\mathrm{s} \mid \ll \mathrm{A}$ knows $\mathrm{X} \gg \wedge \ll \mathrm{B}$ knows $\mathrm{X} \gg \wedge \ll \mathrm{A}$ knows $\mathrm{p} \gg \wedge \ll \mathrm{B}$ knows $\mathrm{p} \gg$

where $p$ is the very proposition about A's and B's knowing p (cf. Devlin 1997, 255.). The analysis is circular and selfreferential. Its advantage consists in the principal garantee that everything in the common knowledge situation available for $\mathrm{A}$ is to the same extent available for $\mathrm{B}$ and vice versa. Consequently, with regard to the Gricean framework, the speaker ist not more privileged in meaning something than his addressee is in understanding what the speaker meant.

My purpose of this part of my paper actually is to give an account of how underdetermined utterances or parts of them can be interpreted by a hearer in accordance to the speaker's meaning. Till now, we have only considered the case of the black kettle, a case where the utterance had to be re-interpreted. What's about the open-, office- or institute-cases mentioned in part 1 and 2 of my paper? In these cases the hearer has to determine what concept of all possible concepts is the one meant by th e speaker. Does he really have to work out the speaker's meaning by a Gricean implicature, as it seems plausible for the black kettle case (as well as for other cases like metaphorical uses, rhetorical questions, tautologies and irony)? Sure, if we assume that we have stored all the possible concepts for open in our mental lexicon and that we have clear devices for accessing them, the Gricean mechanism would be unnecessary. But this is not the case: the possible concepts for open (and legions of other words like cut, write, fly, eat, begin, end or compute) are indefinite, and we don't have singular situations in mind as pointers to linguistic expressions: what we have stored in long term memory are situation types related to types of words, if any.

What special kind of implicature would be efficient to determine the conceptual content of open in a given context and situation? A speaker utters

(3) The plumber opened the washing machine yesterday, but he couldn't find any defect

meaning that the plumber unscrewed the machine. Are the conceptual components of the utterance sufficient for the hearer to understand that the plumber unscrewed the machine? Surely not, the plumber could just have opened the lid of the machine and looked into it or he could have done both, opened the lid and unscrewed the machine. So, the hearer has the choice between 'unscrewing the machine", 'opening the lid' and 'opening the lid and unscrewing the machine'. Is it our knowledge about the world that determines meaning in context? If so, what kind of re al, normal or expected world should this be? I think there 
is no way out of relying only on linguistic context and individual background knowledge. We first have to account for the hearer's presumption of the speaker's cooperative acting, especially his being relevant. Assuming that the speaker intends to communicate relevant information, the hearer's background knowledge presupposed by him to be the speaker's and the hearer's common knowledge is activated, and this allows him to recognize the speaker's int ended meaning, that the plumber has unscrewed the washing machine.

Though this is a very weak implicature, it clearly illustrates that even in rather unspectacular cases of interpretation, pragmatic aspects related to acting, play a fundamental role. The lexicon of a language, conceptual knowledge and communicative acting are inseperately interrelated within human cognitive systems unlike artificial ones.

\section{References}

1. Bach, K. (1999): The Myth of Conventional Implicature. In: Linguistics and Philsophy 22, 327-366.

2. Bach, K. (1999): The Semantics-Pragmatics Distinction. What It is and Why It Matters. In: Turner, K. (ed.): The Semantics/Pragmatics Interface from Different Points of View. Oxford/Amsterdam etc.: Elsevier, 65-84.

3. Berg, J. (1991): The relevant relevance. In: Journal of Pragmatics 16, 411-425.

4. Bierwisch, M. \& E. Lang (1989): Dimensional Adjectives: Grammatical structure and conceptual interpretation. Heidelberg: Springer.

5. Bierwisch, M. \& R. Schreuder (1992): From concepts to lexical items. In: Cognition 42, 23-60.

6. Carston, R. (1999): The Semantics/Pragmatics Distinction: A View from Relevance Theory. In: Turner, K. (ed): The Semantics/Pragmatics Interface from Different Points of View. Oxford/Amsterdam etc.: Elsevier, 85-126.

7. Devlin, K. (1997): Goodbye, Descartes. The End of Logic and the Search for a New Cosmology of the Mind. New York etc.: Wiley.

8. Dölling, J.(1992): Flexible Interpretation durch Sortenverschiebung. In: Zimmermann, I. \& A. Strigin (ed.): Fügungspotenzen. Berlin: Akademie-Verlag, 23-62.

9. Fauconnier, G. (1985): Mental Spaces: Aspects of Meaning Constructions in Natural Language. Cambridge/Mass.: MIT Press.

10. Fellbaum, Ch. (1996): WordNet: Ein semantisches Netz als Bedeutungstheorie. In: Grabowski, J./Harras, G. \& Th. Herrmann (eds.): Bedeutung - Konzepte Bedeutungskonzepte. Opladen: Westdeutscher Verlag, 211-230.

11. Grice, H.P. (1989): Studies in the Way of Words.Cambridge/Mass.: Harvard University Press.

12. Harras, G. (1991): Zugänge zu Wortbedeutungen. In: Harras, G./Haß, U. \& G. Strauß (eds.): Wortbedeutungen und ihre Darstellung im Wörterbuch. Berlin/New York: de Gruyter, 3-96.

13. Jackendoff, R (1997): The Architecture of the Language Faculty. Cambridge/Mass.: MIT Press.

14. Jackendoff, R. (1983): Semantic and Cognition. Cambridge/Mass.: MIT Press

15. Jackendoff, R. (1990): Semantic Structures. Cambridge/Mass.: MIT Press.

16. Johnson-Laird, P.N: (1987): The mental representation of the meaning of words. In: Cognition 25, 189-211. 
17. Kamp, H. \& M. Reyle (1993): From Discourse to Logic. Dordrecht: Kluwer.

18. Katz, J. \& J. Fodor (1963): The Structure of a Semantic Theory. In: Language 39, 170-210.

19. Keller, R. (1995): Zeichentheorie. Tübingen/Basel: Francke UTB.

20. Krifka, M. \& K. Wenger (1990): Gradierung und Dimension. Eine Diskussion von "Grammatische und konzeptuelle Aspekte von Dimensionsadjektiven". In: Linguistische Berichte 130, 478-504.

21. Lakoff, G. (1987): Women, Fire and Dangerous Things. What Categories Reveal about the Mind. Chicago: University of Chicago Press.

22. Lang, E. (1994): Semantische vs. konzeptuelle Struktur. Unterscheidung und Überschneidung. In: Schwarz, M. (ed): Kognitive Semantik/Cognitive Semantics. Tübingen: Narr, 25-40.

23. Langacker, R. (1988): A View of Linguistic Semantics. In: Rudzka-Ostyn, B. (ed): Topics in Cognitive Linguistics. Amsterdam: Benjamins, 49-90.

24. Lutzeier, P. (1985): Linguistische Semantik. Stuttgart: Sammlung Metzler.

25. Lyons, J. (1977): Semantics. Vol 1. Cambridge: Cambridge University Press.

26. Meyer, R. (1994): Probleme von Zwei-Ebenen-Semantiken. In: Kognitionswissenschaft $4,32-46$.

27. Pinkal, M. (1995): Logic and Lexcon. Dordrecht: Kluwer.

28. Pustejovsky, J. (1995): The Generative Lexikon. Cambridge/Mass.: MIT Press.

29. Putnam, H. (1975): The Meaning of Meaning. In: Gunderson, K. (ed): Language, Mind, and Knowledge. Minneapolis: University of Minnesota Press, 131-193.

30. Schwarz, M. (1992): Kognitive Semantiktheorie und neuropsychologische Realität. Repräsentationale und prozedurale Aspekte der semantischen Kompetenz. Tübingen: Niemeyer.

31. Schwarze, Ch. (1987): Text Understanding and Lexical Knowledge. In: Verschueren, J. \& M. Bertucelli-Papi (eds.): The Pragmatic Perspective. Amsterdam: Benjamins, 587-612.

32. Searle, J. (1980): Literal Meaning. In: Searle, J.: Expression and Meaning. Cambridge: Cambridge University Press, 117-136.

33. Sperber, D. \& D. Wilson (1995): Relevance. Communication and Cognition. Second edition. London: Blackwell.

34. Sperber, D. \& D. Wilson (1998): The Mapping between the mental and the public Lexicon. In: Carruthers, P. \& J. Boucher (eds.): Thought and Language. Cambrdge: Combridge University Press, 184-200.

35. Travis, C. (1997): Pragmatics. A Companion to the Philosophy of Language. In: Hale, B. \& C. Wright (eds.): Pragmatics. Oxford: Blackwell, 87-107.

36. Wierzbicka, A. (1972): Semantic Primitives. Frankfurt/M.: Athenäum.

37. Wunderlich, D. (1997): Cause and the Structure of Verbs. In: Linguistic Inquiery $28,27-68$.

38. Ziv, Y. (1988): On the Rationality of 'Relevance' and the Relevance of 'Rationality'. In: Journal of Pragmatics 12, 535-545. 